\title{
A MIXTURE OF GOS/FOS $\circledast$ ADDED TO A LOW CALCIUM (Ca) DIET IMPROVED Ca, PHOSPHORUS (P) AND MAGNESIUM (Mg) ABSORPTION: EXPERIMENTAL MODEL IN NORMAL GROWING RATS
}

G. Bryk ${ }^{1}$, M. Gonzales Chaves ${ }^{1}$, C. Marotte ${ }^{1}$, D. Medina ${ }^{1}$, M. Zeni Coronel M ${ }^{1}$, M. L. de Portela ${ }^{3}$, S. N. Zeni

1) Laboratorio de Enfermedades Metabólicas Óseas, Hospital de Clínicas, Instituto de Inmunología, Genética y Metabolismo (INIGEM) CONICET-UBA; 3) Catedra de Nutricion. Facultad de Farmacia y Bioquímica UBA.

\section{Introduction:}

If $\mathrm{Ca}$ intake (Cal) is inadequate, a mixture of Galactooligosaccharides (GOS) and Fructo-oligosaccharides (FOS) (®) added to the diet could be an optimal tool to improve $\mathrm{Ca}, \mathrm{P}$ and $\mathrm{Mg}$ absorptions and, thus promoting bone health.

\section{Objective:}

The effect of feeding a low $\mathrm{Ca}$ diet containing a mixture of GOS/FOS $\AA^{\circ}$ (usually added to infant formula) was evaluated in an experimental model of normal growing rats to demonstrate: 1) changes in intestinal $\mathrm{pH}, 2$ ) enhances in the absorption of $\mathrm{Ca}, \mathrm{Mg}$ and $P, 3$ ) increases in bone mineral density and content (BMD and $\mathrm{BMC}$, respectively).

\section{Materials and Methods}

At weaning, Wistar male rats $(36 \pm 5 \mathrm{~g})$ were fed one of three experimental diets to 40 days of age. The groups were the following :

A5: AIN93G containing $0.5 \% \mathrm{Ca}$

A3: AIN93G containing $0.3 \% \mathrm{Ca}$

GF3: AIN93G containing $0.3 \% \mathrm{Ca}$ and $5.3 \% \mathrm{GOS} / \mathrm{FOS} \AA$.

Food consumption and body weight (BW) were recorded 3 times/week. $\mathrm{Ca}, \mathrm{Mg}$ and $\mathrm{P}$ absorption percentage was determined at weaning $(T=21)$ and during the last 3 days of the study $(\mathrm{T}=40)$. At the end of the study caecal $\mathrm{pH}$ was measured and total skeleton (tsk) BMD, and tibia BMD were evaluated by DXA

\section{Results}

At $\mathrm{T}=21 \mathrm{~d}$ : No differences in $\mathrm{pH}, \mathrm{Ca}, \mathrm{P}$ and $\mathrm{Mg}$ absorptions and tskBMD or tibia BMD were found. Through the study, no differences in BW increase was observed among groups.
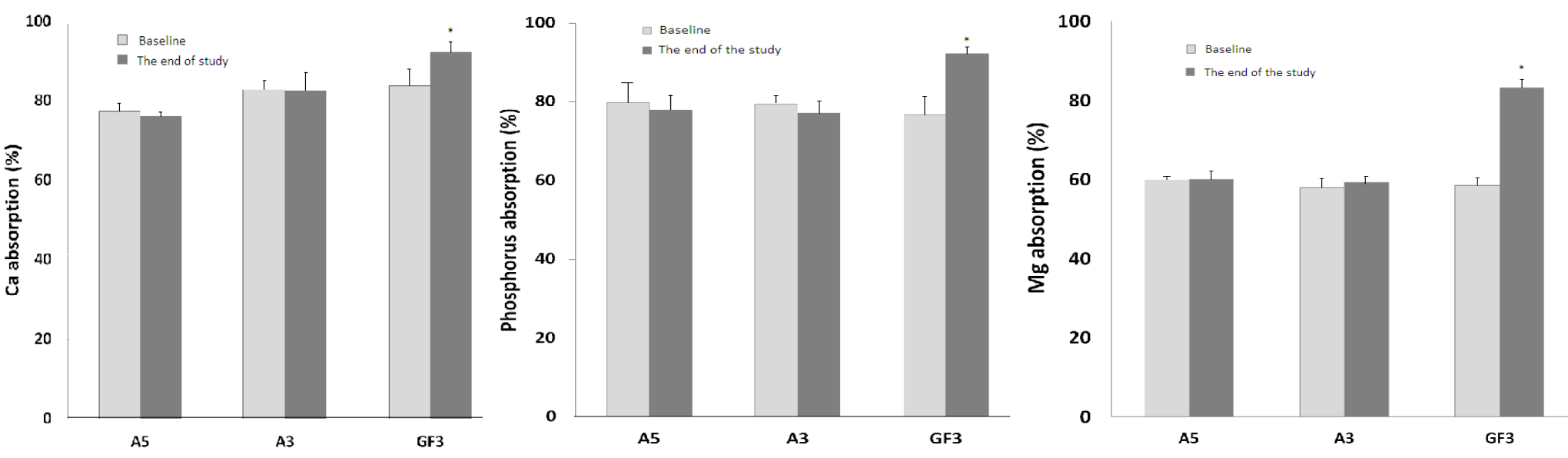

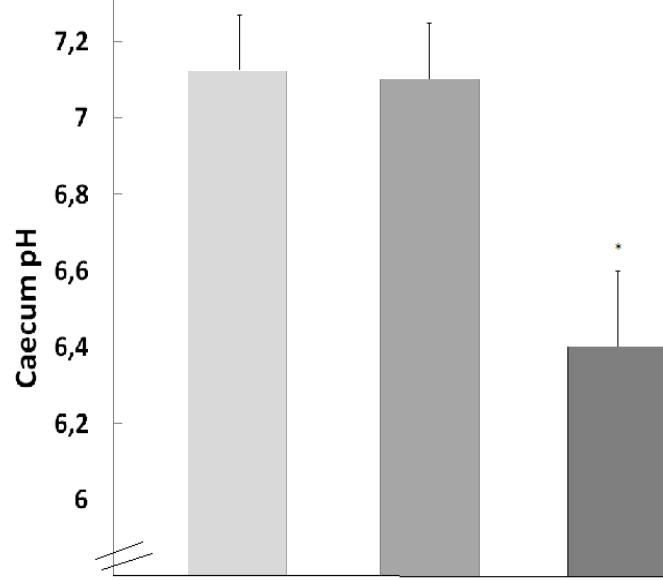

A5

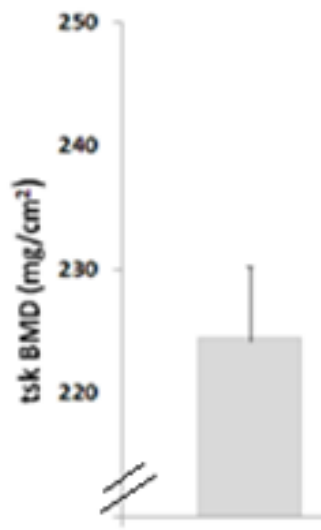

AS

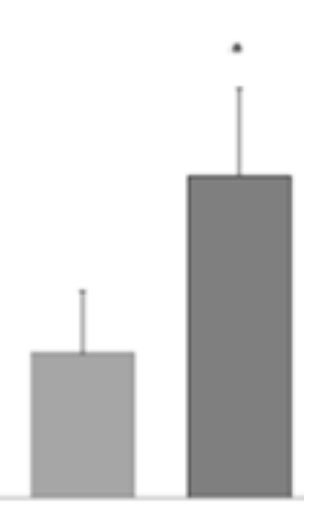

GF3

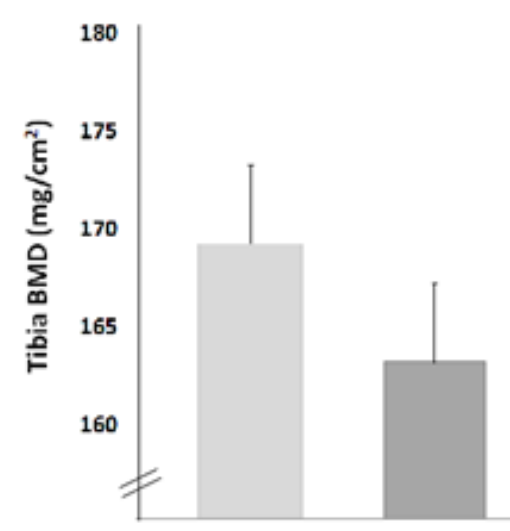

A.3

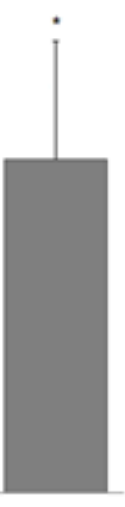

GF3

$\left(^{*}\right): P<0.01$ compared to GF3 at baseline and compared to A5 and A3 at the end of the study

\section{CONCLUSION:}

Discussion: These results evidence a decrease in caecum $\mathrm{pH}$ and an increment in $\mathrm{Ca}, \mathrm{Mg}$ and $\mathrm{P}$ absorption percentage by feeding the low Ca diet containing GOS/FOS ${ }^{8}$. These grater absorption induce an increase in BMD both at cortical and trabecular level suggesting an increment in bioavailability.

Conclusion:These results confirm the benefic effect of GOS/FOS® in bone health during normal growth. 